\title{
Individual characteristics in early life relate to variability in weaning age, feeding behavior, and weight gain of dairy calves automatically weaned based on solid feed intake
}

\author{
Heather W. Neave, Joao H. C. Costa, ${ }^{*}$ J. B. Benetton, Daniel M. Weary, and Marina A. G. von Keyserlingk† \\ Animal Welfare Program, University of British Columbia, 2357 Mall, Vancouver, BC, Canada, V6T 1 Z4
}

\begin{abstract}
Little is known about factors affecting individual variability in weaning age, feeding behavior, and growth of dairy calves. The objectives of this study were to (1) describe early-life individual characteristics of dairy calves and how these relate to weaning age, feeding behavior, and performance during the first 15 wk of age, and (2) to identify which of these individual characteristics predict weaning age of calves automatically weaned based on solid feed intake. Early-life characteristics of calves $(\mathrm{n}=43)$ included scores for vitality at birth, drinking ability, learning ability to use the automated milk feeder in a group pen from $\mathrm{d} 1$ of age, and personality traits assessed using exposure to a novel environment, a human, and an object at d 21 of age. Calves received $12 \mathrm{~L} / \mathrm{d}$ of milk until d 30 when milk was reduced by $25 \%$ relative to the individual's previous 3-d intake average. Calves were weaned based on intake of solid feed (milk reduced by $25 \%$ at each of 2 intermediate solid feed intake targets, 225 and $675 \mathrm{~g} / \mathrm{d}$ ), and were weaned when they consumed 1,300 $\mathrm{g} / \mathrm{d}$ of solid feed, resulting in variable weaning ages. A principal component analysis identified 5 factors that we labeled as low vitality, fearful, strong drinker, slow learner, and exploratory-active. Calves that were slow learners weaned at a later age, whereas fearful calves weaned earlier. No other early-life individual characteristics were associated with weaning age. Other characteristics (low vitality, strong drinkers, and exploratoryactive) were associated with some measures of feeding behavior, feed intake, and growth, especially during the preweaning period. Measures of early solid feed intake (age to start eating and total preweaning intake) were best able to predict weaning age of calves. Individual
\end{abstract}

\footnotetext{
Received February 6, 2019.

Accepted June 29, 2019.

*Present address: Department of Animal and Food Sciences, University of Kentucky, 325 Cooper Dr., Lexington, KY 40546.

†Corresponding author: nina@mail.ubc.ca
}

early-life characteristics and measures of early solid feed intake can identify calves likely to do well or struggle during weaning.

Key words: temperament, vigor, precision dairy, animal welfare, personality

\section{INTRODUCTION}

Individual variability in milk and calf starter intakes of dairy calves before and after weaning has been observed across several studies (e.g., Nielsen et al., 2008; de Passillé and Rushen, 2016; Neave et al., 2018a). Some calves begin to consume calf starter at a young age (Neave et al., 2018a), and others take up to $11 \mathrm{wk}$ to consume just $200 \mathrm{~g} / \mathrm{d}$ of calf starter (de Passillé and Rushen, 2016). Calves also vary in when they are able to complete weaning based on intake of calf starter, with some weaning as early as 6 wk of age (Roth et al., 2009; Benetton et al., 2019) or as late as 13 wk of age (de Passillé and Rushen, 2016). This variability in calf starter intake and age of weaning likely contributes to the variability in weight gains seen across studies (e.g., 0.1 to $1.6 \mathrm{~kg} / \mathrm{d}$; Soberon et al., 2012), which can have important consequences. For example, high preweaning DMI and weight gains have been linked to improved milk production and reproductive outcomes (e.g., Raeth-Knight et al., 2009; Gelsinger et al., 2016).

Understanding is limited of why calf performance varies when calves are fed and housed under similar conditions. Some authors have attributed variability to differences in season of birth, parity of the dam, management factors, genetics, or health (e.g., Place et al., 1998; Heinrichs and Heinrichs, 2011). Shivley et al. (2018) found several factors affecting preweaning ADG on US dairy operations, including measures related to calving, colostrum, feeding and housing practices, nutrient intake composition, climate, and disease. However, their models did not include behavioral factors known to contribute to preweaning calf performance. For instance, Gilbert et al. (2017) showed that drinking speed and fearfulness (response to human contact and 
movement on a weigh scale) were negatively associated with weight gain in veal calves, and Neave et al. (2018a) found that personality traits in dairy heifers (such as interactive, exploratory, and vocal responses when exposed to novel situations) were related to feeding behavior and performance before and during weaning. Behavioral measures in these studies were taken when calves were several weeks to several months of age; it is possible that other behaviors recorded at an early age may explain variability in feeding behavior, growth, and suitability to wean early.

One of the first measures available is vitality at birth and in the first few hours of life (reviewed by Murray and Leslie, 2013). Calves with low vitality have reduced weight gain at $14 \mathrm{~d}$ of age (Furman-Fratczak et al., 2011; Murray et al., 2015), take longer to learn to use automated milk feeders, and have reduced milk intake in the first 2 wk of life (Fujiwara et al., 2014). Calves that required more time to learn to drink from the milk feeder had reduced weight gain at $30 \mathrm{~d}$ of age (Medrano-Galarza et al., 2018). These characteristics may also influence how individuals cope with environmental stressors such as weaning, and thus how early calves will wean. Differences in individual traits such as fearfulness, sociability, and exploration can also explain why some individuals struggle to adapt to changes in their feeding environment (for review, see Neave et al., 2018b).

Dairy calves are normally weaned at a set age (e.g., Canada: Vasseur et al., 2010; Brazil: Hötzel et al., 2014; Czech Republic: Staněk et al., 2014; the United States: Shivley et al., 2018), but automated milk and calf starter feeders can be used to wean calves based on individual calf starter intakes (Roth et al., 2009; de Passillé and Rushen, 2012, 2016). In this way computer-controlled feeders can be used to allocate milk resources away from calves that begin to consume calf starter early, and toward calves requiring more time on milk before weaning (Benetton et al., 2019). However, it is not clear how best to predict which calves are suitable candidates for early weaning. No study to date has investigated which measures can predict suitability of dairy calves for early weaning when allowed to wean based on solid feed intake.

The first objective of this study was to describe earlylife individual characteristics of dairy calves measured in the first $30 \mathrm{~d}$ of age (specifically vitality, drinking and learning ability, and personality traits) and their relationship with weaning age, feeding behavior, and performance during the first $15 \mathrm{wk}$ of age when weaned based on individual intake of solid feed. We predicted that calves with low vitality and poor learning ability would wean later, and that more exploratory calves would wean earlier. The second objective of this study was to identify which measures in the first $30 \mathrm{~d}$ of age (including early-life individual characteristics measured in the first objective, automatically recorded feeding behaviors, and growth) are the best predictors of weaning age. Of these measures, we predicted that high solid feed intake in the first $30 \mathrm{~d}$ would be the best predictor of early weaning age.

\section{MATERIALS AND METHODS}

The study was conducted from July 2017 to March 2018 at the University of British Columbia Dairy Education and Research Centre in Agassiz, BC, Canada, and was approved under the University of British Columbia Animal Care protocol \#A14-0245. This study was part of a companion study published as Benetton et al. (2019), which reports the performance of calves in the current study that completed weaning early versus late when weaned based on solid feed intake.

\section{Housing and Animal Management}

Detailed animal management, housing, and weaning protocols for this experiment can be found in Benetton et al. (2019). Briefly, 48 Holstein calves (45 females and 3 males) were enrolled in this study from the same population of calves reported in experiment 2 of Benetton et al. (2019). This sample size was selected on the basis of achieving sufficient variability in weaning ages, with a target of at least 8 calves weaned between 6 to $7 \mathrm{wk}, 7$ to 8 wk, 8 to 9 wk, and after 9 wk of age. Based on the data from experiment 1 in Benetton et al. (2019), we expected the fewest number of calves to wean during wk 6 to 7 (approximately $19 \%$ of calves); therefore, a population of 43 calves was required for this experiment. Calves remained with their dam for 5 $\mathrm{h}$ after birth, and were then separated, weighed (mean $40.3 \pm 5.9 \mathrm{~kg}$ ), and moved into individual pens where $4 \mathrm{~L}$ of colostrum was fed using a nipple bottle within $6 \mathrm{~h}$ after birth. At the next a.m. or p.m. feeding following the colostrum meal, $4 \mathrm{~L}$ of whole milk was fed through a nipple bottle in the individual pen. Calves were moved into a sawdust-bedded group pen $(4.87 \times$ $7.31 \mathrm{~m}$ ) $1 \mathrm{~h}$ before their second milk meal (nominally $1 \mathrm{~d}$ of age). Group pens were filled to 8 calves based on birth date, and then a new pen was started (for a total of 6 group pens). After their first milk meal in the group pen (24 to $30 \mathrm{~h}$ after colostrum feeding), a blood sample was collected from the jugular vein for serum analysis using a Reichert AR 200 Digital Handheld Refractometer (Reichert, Depew, NY). All calves achieved passive transfer as identified by serum total protein $>5.2 \mathrm{~g} / \mathrm{dL}$. 


\section{Feeding and Weaning Program}

Each group pen was equipped with an automated milk feeder (CF 1000 CS Combi, DeLaval Inc., Tumba, Sweden) with one teat providing access to pasteurized whole milk. The milk feeder delivered milk in $0.5-\mathrm{L}$ portions. The milk allowance accrued hourly at a rate of $5 \%$ of the daily value every hour from midnight to 2000 h. Calves were otherwise allowed to split their milk allowance in as many visits as they wish. Calf starter (Advantage 4 Med, Trouw Nutrition, Chilliwack, BC, Canada) was fed ad libitum and controlled from the same automated feeder. The feeder recorded intake, time, and duration of each milk and calf starter visit. Farm hay mixture of festulolium [tall fescue (Festuca arundinacea $) \times$ ryegrass (Lolium perenne L.) cross], orchard grass (Dactylis glomerata L.), and ryegrass (Lolium perenne L.)\} and water were available ad libitum from automatic feeders (RIC, Insentec B. V., Marknesse, the Netherlands). Feeding behavior at the hay feeder and hay intake could not be reliably measured throughout the experiment and thus is not reported. Calibration of all automated feeders was performed every second week for each group pen to verify accurate dispensing and intake of milk and calf starter portions.

All calves were assigned to a weaning plan that combined 2 weaning techniques: a step-down reduction in milk at $30 \mathrm{~d}$, and subsequent milk reduction based on individual calf starter intake. Calves were offered 12 $\mathrm{L} / \mathrm{d}$ of milk from d 1 until nominally d 30 of age (mean $31.3 \pm 1.15 \mathrm{~d}$ ). On d 31, milk was reduced by $25 \%$ relative to each individual's average milk intake over the previous $3 \mathrm{~d}$. The timing of subsequent $25 \%$ reductions in milk were based upon when the calf consumed specific amounts of calf starter: 225, 675, and 1,300 $\mathrm{g} / \mathrm{d}$ of calf starter (approximately 0.5, 1.5, and $3 \mathrm{lb}$, respectively, as recommended by the Bovine Alliance on Management and Nutrition, 2017). To qualify for the milk reduction, the calf needed to consume the target calf starter consumption on average across the preceding $3 \mathrm{~d}$, but with a daily minimum of $50 \%$ of the target. Calves were permitted up to $\mathrm{d} 84$ of age to reach all 3 intake targets; if a calf did not consume $1,300 \mathrm{~g} / \mathrm{d}$ of calf starter by d 84, the calf was gradually weaned by reducing the milk over $7 \mathrm{~d}$, beginning from the calf's current milk allowance until weaning was completed at d 91. Calves remained in their group pen until the last calf from the group reached $105 \mathrm{~d}$ of age.

Milk samples were collected and analyzed for components once per week (Pacific Milk Analysis Lab, Chilliwack, BC, Canada). Calf starter and hay samples were analyzed as reported in Benetton et al. (2019).

\section{Health Measures}

Health examinations were performed as described in Benetton et al. (2019) for purposes of controlling for the effect of illness on outcome measures (health was not considered an outcome measure). Health examinations consisted of diarrhea scoring while calves stood on an individual weigh scale, where $1=$ normal feces; 2 $=$ plaques but not watery; 3 = watery and body temperature $<39.5^{\circ} \mathrm{C} ; 4=$ watery and body temperature $\geq 39.5^{\circ} \mathrm{C}$. Calves with severe diarrhea were treated with electrolytic solutions (Hydrafeed, EXL Laboratories, Minneapolis, MN), and calves failing to respond to treatment within $2 \mathrm{~d}$ were administered a nonsteroidal anti-inflammatory drug (NSAID; Metacam $20 \mathrm{mg} /$ $\mathrm{mL}$, Boehringer Ingelheim, Burlington, ON, Canada), according to our farm's standard procedure. Clinical examinations of respiratory health were performed by lung auscultation $(0=$ no lung consolidation detected; 1 = some lung consolidation; 2 = lung consolidation); calves showing nasal discharge and pathological sounds of pulmonary infection $($ score $=2$ ) were treated with antibiotic drugs (Resflor GOLD, Intervet Inc., Roseland, NJ, or Draxxin, Zoetis Inc., Parsippany, NJ). It is possible this method of assessing respiratory health missed some cases of subclinical illness, but we expected clinical (versus subclinical) cases to be the most likely to affect our outcome measures. Calves were also visually examined twice per day (morning and afternoon) and any calves that were seen to have diarrhea or ill thrift (unresponsive to human presence at the front of the pen, head or ears down) were given a complete health examination and treatment was administered as necessary. A total of 14 calves were treated for respiratory infection with antibiotics $(\mathrm{n}=9)$, diarrhea with electrolytes, fever with a NSAID $(\mathrm{n}=5)$, or a combination of these.

\section{Measures of Feeding Behavior, Weaning Age, and Growth}

Daily milk and solid feed intake, and the number of rewarded (when the calf visited the feeder and received milk) and unrewarded (when the calf visited the feeder but did not receive milk) visits to the milk feeder were recorded by the automated feeding system. Each of these measures was calculated as a daily average for 4 experimental periods: preweaning (full milk allowance; d 1 to 30 of age), weaning (from initial milk reduction to end of required weaning period; d 31 to 91), postweaning (d 92 to 105 of age), and the total experimental period (d 1 to 105 of age). Additional measures 
for the total experimental period included cumulative milk and calf starter intake, ADG ( $\mathrm{kg}$ of $\mathrm{BW} / \mathrm{d}$ ), and final weight at completion of the experiment at d 105 .

We described the development of solid feed intake behavior and behavioral response to weaning for each calf following Neave et al. (2018a). Early solid feed intake measures included the age $(\mathrm{d})$ that each calf first ate at least $40 \mathrm{~g}$ of solid feed from the feeder (indicating the calf ate at least the first $20 \mathrm{~g}$, which is the smallest portion dispensed by the feeder), and the age that each calf met each of the solid feed intake targets (225, 675 , and $1,300 \mathrm{~g}$ ). Weaning age was the age that calves consumed 1,300 g/d of solid feed (or d 91 for those calves that failed to reach this target). To describe the behavioral response to weaning for each calf, the total number of unrewarded visits to the milk feeder during the first week after weaning was calculated (i.e., from the day of weaning to $7 \mathrm{~d}$ postweaning); this measure was meant to capture how persistent the calf was in attempting to gain milk from the feeder.

\section{Measures of Early-Life Individual Characteristics}

Vitality. During the $5 \mathrm{~h}$ that the calf remained with the dam, video was recorded continuously using 4 cameras (WV-CW504SP, Panasonic, Osaka, Japan) positioned above the maternity pen. The latency to reach sternal recumbency, attempt standing, stand, walk, and suckle the dam were recorded from video (Supplemental Table S1, https://doi.org/10.3168/jds.2019-16438). Longer latencies indicate lower vitality (Murray and Leslie, 2013). After separation from the dam, the calf was transported to the calf barn where additional vitality measures were taken (Supplemental Table S2, https: //doi.org/10.3168/jds.2019-16438; following Vannucchi et al., 2012; Murray, 2014), including respiration rate, heart rate, standing with or without stimulation, reflex, and rectal temperature. Scores were tallied such that a higher total indicated higher vitality.

Drinking Ability. Immediately following vitality scoring, calves were offered $4 \mathrm{~L}$ of colostrum from two 2-L nipple bottles. Calves were scored for drinking response during this feeding (strong, medium, or weak sucking; following an ethogram described in Supplemental Table S2, https://doi.org/10.3168/jds .2019-16438), and during a second colostrum feeding (offered $15 \mathrm{~min}$ after first attempt if the $4 \mathrm{~L}$ was not fully consumed). If more than $3.5 \mathrm{~L}$ of colostrum was consumed, calves were not tubed (score 1); and if less than $3.5 \mathrm{~L}$ of colostrum was consumed, calves were tube-fed the remainder of the colostrum (score 0). A colostrum drinking score was tallied for a maximum score of 4 , with a higher score indicating a stronger suck. At the first milk feeding after colostrum feeding, a total of $4 \mathrm{~L}$ of whole milk was offered in two 2-L nipple bottles; drinking score for this first milk meal was scored identically to that for colostrum feeding, and "first milk meal drinking score" was tallied for a maximum score of 4 , with a higher score indicating a stronger suck. Total milk consumption from the first milk meal was also recorded.

Learning Ability. Once calves entered the group pen they were trained to drink from the milk feeder following a training protocol. Human assistance was offered for each calf twice per day at 0900 and 1700 $\mathrm{h}$ until learning was achieved (2 L of milk consumed between feedings without human assistance). When calves first entered the group pen they were permitted $1 \mathrm{~h}$ to attempt to access and drink from the milk feeder on their own before assistance was offered. At each feeding (0900 and $1700 \mathrm{~h}$ ), if a calf had not yet visited the feeder on her own and consumed at least $2 \mathrm{~L}$ of milk, the trainer entered the calf pen and stood next to the milk feeder; if the calf did not enter the feeder and begin to drink on her own, the trainer approached the calf and offered her hand (without permitting suckling) to guide the calf into the feeder. If the calf did not follow, the human gently pushed the calf from the back into the feeder while allowing the calf to suck her fingers. Once in the feeder, the calf was permitted 10 $\mathrm{s}$ to find the teat on her own. If the calf was unable to find the teat, the trainer allowed the calf to suck her fingers and guided the calf's mouth onto the nipple. This action was tallied as a teat demonstration. If the calf stopped sucking on the teat it was permitted $5 \mathrm{~s}$ to re-locate the teat before assistance was again offered (as described earlier). This pattern was repeated until the calf consumed at least $2 \mathrm{~L}$ of milk. If the calf did not begin to suck on the teat after 5 teat demonstrations, a nipple bottle was offered while inside the milk feeder to stimulate a suckling response. Once the calf was successfully sucking from the nipple bottle, the calf was transferred back to the milk feeder teat following the above protocol. The total number of teat demonstrations until $2 \mathrm{~L}$ of milk was consumed (including the number of demonstrations required using a nipple bottle) was tallied per feeding, and then a grand total of teat demonstrations across all feedings requiring human assistance was calculated. The number of feedings sessions requiring human assistance was also tallied.

Responses to Novelty. Standardized personality tests (novel environment, human approach, and novel object tests) were used following Neave et al. (2018a). Briefly, calves were tested individually in a sawdustbedded pen similar to the home pen except that the feeding equipment was inaccessible. Testing occurred 
over 3 consecutive days in the week before initial milk reduction (nominally $25 \mathrm{~d}$ of age, $25.3 \pm 2.3 \mathrm{~d}$ ). At the time of testing, the calf was guided gently into the test pen. Each calf remained in the test arena for 30, 10, and $10 \mathrm{~min}$ for the novel environment, human approach, and novel object tests, respectively. The novel environment test consisted of an empty arena. In the human approach test, a female human, unknown to the calf and dressed in dark coveralls with hands in the coverall pockets, stood immobile at the center of the test pen looking toward the feet of the calf. In the novel object test, a black 140-L bucket was placed at the center of the test pen. The calf was video recorded continuously using one camera (WV-CW504SP, Panasonic) positioned $7 \mathrm{~m}$ above the test pen. A single observer scored all behaviors after establishing high inter- and intraobserver reliability $\left(\kappa_{\mathrm{W}}>0.81\right)$ for each test following an ethogram (Supplemental Table S1, https://doi.org/ 10.3168/jds.2019-16438). Vocalizations were recorded by an observer that was out of sight of the test arena. Calves that never touched the human or object were assigned the maximum latency (10 min).

\section{Statistical Analysis}

All analyses were performed using SAS (version 9.4, SAS Institute Inc., Cary, NC) with calf as the experimental unit. Three calves failed to wean (did not meet the final calf starter intake target before 12 wk of age), so they were excluded due to a low sample size for this weaning outcome, and 2 calves were excluded due to multiple antibiotic treatments during the experiment, leaving 43 calves in our final analyses.

Behaviors recorded as durations in the personality tests were expressed as a percentage of the total test time. Bucking, resting, and withdrawals rarely occurred during the tests and were excluded from further analysis. Behaviors recorded in both novel object and human approach tests were averaged across tests (following Neave et al., 2018a, and Lecorps et al., 2018), resulting in 5 behavioral measures (number of vocalizations, latency to touch, and duration of touching, playing, and attentive) and a further 3 behavioral measures for the novel environment test (duration of active, inactive, and exploring). All measures of individual characteristics, feeding behavior, and performance were verified for normality using the PROC UNIVARIATE procedure and probability distribution plots. All variables deemed not normal were normalized as required using $\log _{10}$ or square-root transformations (the specific transformed variables are identified in Table 2). Model residuals were also scrutinized to verify normality (using box, distribution, and probability plots) and homogeneity of variances. Calves were classified as sick if they had a score of 3 or higher for diarrhea, had a score of 2 for lung consolidation, were treated with NSAID or antibiotics, or had any combination of the above at any point during the experiment.

To address our first objective, we subjected the response variables to a principal component analysis (PCA) with varimax rotation (using PROC FACTOR in SAS) to condense correlated measures into principal components. These 20 response variables reflected early-life individual characteristics of calves including measures of vitality (6 measures: latency to reach sternal recumbency, first standing attempt, stand, walk, suckle from the dam, and vigor score), drinking ability (4 measures: colostrum drinking score, first milk meal drinking score, first milk meal intake, average milk intake during first week), learning ability $(2$ measures: total number of feedings, and number of teat demonstrations required to learn to drink from the automated milk feeder), and personality measures (8 measures, described above). We retained 5 principal components following examination of the scree plot of eigenvalues; these 5 principal components (referred to as factor 1 through 5 hereafter) had eigenvalues $>1.5$ and explained $66 \%$ of the variance. High loadings on each principal component were considered greater than \pm 0.50 . For each calf, the score on each factor was extracted; this score indicates where each calf lies along an axis from highly positive to highly negative on each factor. We tested whether each of these factors (reflecting particular early-life individual characteristics) affected weaning age (i.e., age to eat $1,300 \mathrm{~g} / \mathrm{d}$ of solid feed), feeding behavior, and performance during each of the 4 experimental periods (preweaning, weaning, postweaning, and total experiment). Using PROC MIXED, a single analysis was conducted to test for the effects of each factor (1, 2, 3, 4, and 5) on milk intake, calf starter intake, total DMI, rewarded visits, unrewarded visits, persistent unrewarded visits in the week after weaning, $\mathrm{ADG}$, final BW, age to first eat solid feed, age to eat 225 and $675 \mathrm{~g} / \mathrm{d}$ of solid feed, and weaning age. Initially the model included the fixed effects of each factor score, birth weight, order of entry into the group pen, and sickness (dichotomous variable: sick or healthy), with group as a random effect. Weaning age was also included as a fixed effect for all variables except for the models with outcome measures in the preweaning period, age to first eat 225 and $675 \mathrm{~g} / \mathrm{d}$ of solid feed, and weaning age $(1,300 \mathrm{~g} / \mathrm{d}$ of solid feed). Order of entry into the group pen and sickness were dropped from the model if $P>0.30$; birth weight and weaning age were retained in all models. Significance was declared at $P<$ 0.05 , and tendencies at $0.05<P<0.10$. 
To address our second objective, we performed a multiple regression analysis with backward elimination using PROC MIXED to identify which combinations of variables were best able to predict weaning age of calves that were weaned automatically based on solid feed intake. Explanatory variables initially included were the 5 factors derived from the PCA (reflecting early-life individual characteristics) and 7 variables reflecting feeding behavior and performance in the preweaning period (during the first $30 \mathrm{~d}$ of age): total milk and calf starter intakes, total rewarded and unrewarded visits to the milk feeder, drinking speed, ADG, and age to first eat solid feed. Previous work indicated that age to begin eating calf starter was not necessarily related to how quickly calves increased their consumption (de Passillé et al., 2011); we therefore chose to include measures of calf starter intake in the first $30 \mathrm{~d}$ and age to begin eating calf starter as possible predictors of weaning age when weaning was based on calf starter intake after $30 \mathrm{~d}$ of age. Birthweight, order of entry into the group pen, and sickness were also included in the model. A backward elimination procedure was conducted to identify the best predictors of weaning age. The criterion for a variable to remain in the model was $\alpha<0.15$, with type 1 sum of squares. Group was specified as a random effect.

\section{RESULTS}

\section{Principal Component Analysis}

Measures of early-life individual characteristics (vitality, drinking ability, learning ability, and behavioral responses of calves in each of the novelty tests) are presented in Table 1, and the loadings for each factor are reported in Table 2. Factor 1 explained 23.7\% of the total variance and contained high positive loadings for all latency measures in the maternity pen (time to sternal recumbency, standing attempt, standing, walking, and suckling dam); thus, we labeled factor 1 low vitality. Factor 2 explained $14.3 \%$ of the total variance and had high positive loadings for latency to touch the human or object and time spent attentive and high negative loadings for time spent playing and touching the human or object; thus, we labeled factor 2 fearful. Factor 3 explained $11.7 \%$ of total variance, with high positive loadings for drinking score (colostrum and first milk meal) and for first milk meal intake; factor 3 was labeled strong drinker. Factor 4 explained $9 \%$ of the total variance, with high positive loadings for number of feedings and demonstrations required to learn to use the group feeder and high negative loading for milk intake in the first week; factor 4 was labeled slow learner.
Finally, factor 5 explained $7.6 \%$ of the total variance, with high positive loadings for time spent exploring and active, and number of vocalizations; this was labeled exploratory-active.

\section{Feeding Behavior, Weaning Age, Intake, and Performance}

Development of solid feed intake, weaning age, behavior at the milk and starter feeder, and performance of calves during the experimental period (d 1 to 105 of age) are presented in Table 3. As expected, calves differed in when they began to eat solid feed (mean 36 $\mathrm{d}$, range 18 to $75 \mathrm{~d}$ of age) and when they completed weaning at $1,300 \mathrm{~g} / \mathrm{d}$ of solid feed intake (mean $59 \mathrm{~d}$, range $44 \mathrm{~d}$ to $84 \mathrm{~d}$ of age). Calves also varied in their motivation to access milk, with some showing more than 1,000 unrewarded visits to the milk feeder during the experimental period (mean: 491 visits).

Individual variation was also observed in total feed intake and performance over the experimental period, with calves consuming between 28 and $77 \mathrm{~kg}$ of DM of milk (mean: $47 \mathrm{~kg}$ ) and between 58 and $257 \mathrm{~kg}$ of DM of calf starter (mean: $142 \mathrm{~kg}$ ). Calves also varied in ADG, from 0.8 to $1.2 \mathrm{~kg} / \mathrm{d}$ (mean: $1.0 \mathrm{~kg} / \mathrm{d}$ ).

Some of the observed variation in solid feed intake and weaning age could be explained by early-life individual characteristics. The associations between the 5 factors identified in the PCA and solid feed intake, weaning age, and behavior at the milk and starter feeder during each period (preweaning, weaning, postweaning, and total experiment) are presented in Table 4. Calves that scored highly on factor 4 (slow learner) tended to wean at a later age, but there were no other associations with early solid feed intake. These calves also had fewer preweaning and total rewarded visits to the milk feeder, reduced preweaning drinking speed, and tended to have fewer unrewarded visits before weaning and in the week after weaning, suggesting these calves were less persistent in attempting to access milk. In contrast, calves scoring highly on factor 2 (fearful) tended to wean earlier, and also had reduced drinking speed before weaning. The remaining factors had no associations with development of solid feed intake behaviors or weaning age. However, factor 5 (exploratory-active) was positively associated with preweaning and total rewarded visits to the milk feeder, whereas factor 1 (low vitality) and factor 3 (strong drinker) were negatively associated with these measures.

We also investigated the associations between the factors and feed intake and performance measures during each period (Table 5). Calves that scored highly on factor 4 (slow learner) had reduced preweaning and overall 
DMI, driven primarily by reduced milk intake, resulting in a tendency for reduced preweaning ADG. Calves that scored highly on factor 5 (exploratory-active) had increased preweaning, weaning, and total ADG, resulting in increased final BW; however, this improved growth did not appear to be due to greater milk or calf starter intakes. In contrast, calves that scored highly on factor 1 (low vitality) had reduced preweaning ADG, likely driven by a tendency for reduced preweaning milk intake. Factor 3 (strong drinker) was negatively associated with weaning ADG, but had no associations with milk or calf starter intake. Factor 2 (fearful) had no association with feed intake or performance.

\section{Predicting Weaning Age}

When all variables were included in the regression model, this accounted for $76 \%$ of the variance $\left(\mathrm{R}^{2}\right)$ in weaning age. After backward elimination, 5 explanatory variables were retained in the model: age to start eating calf starter $(P<0.01)$, total preweaning calf starter intake $(P<0.01)$, factor 4 (slow learner; $P<0.01)$, factor 2 (fearful; $P=0.03$ ), and total unrewarded visits $(P$ $=0.08)$. Together these variables explained $67 \%$ of the variance $\left(\mathrm{R}^{2}\right)$. The regression equation (illustrated in Figure 1) was weaning age $=48.4+0.39$ (age to start eating $)-6.98$ (total preweaning calf starter intake) +

Table 1. Mean, SD, and range of measures of vitality at birth, drinking ability, learning ability, and responses to novelty for 43 calves

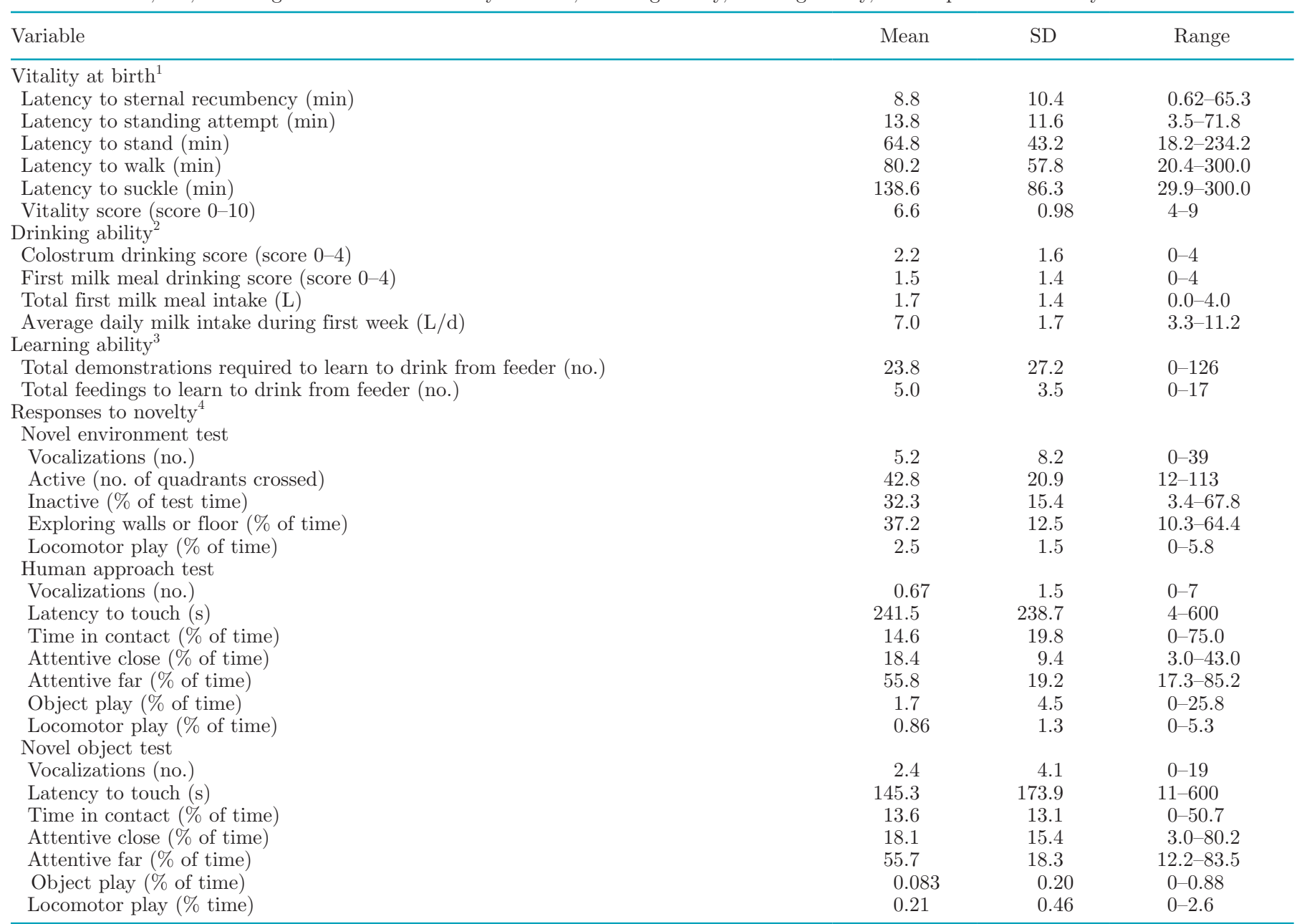

${ }^{1}$ Measured using video recordings when the calf remained with the dam for the first $5 \mathrm{~h}$ after birth. Calves that never performed a behavior were assigned the maximum latency of $300 \mathrm{~min}(5 \mathrm{~h})$. Vitality scoring was performed immediately after separation and after transport to the calf rearing facility.

${ }^{2}$ Measured during colostrum feeding (5-6 h after birth) and during first milk meal (first a.m. or p.m. feeding after colostrum feeding).

${ }^{3}$ Measured beginning from the first entry to the group pen at $1 \mathrm{~d}$ of age until the calf learned to use the automated milk feeder in the group pen without human assistance.

${ }^{4}$ Calves were tested individually in a separate arena from their home pen at $25 \pm 2 \mathrm{~d}$ of age in a novel environment test (30 min), novel object test (10 min), and human approach test (10 min). 
Table 2. Coefficients (loadings) of the eigenvectors for the first 5 factors extracted by principal component analysis of behavioral measures recorded when calves $(\mathrm{n}=43)$ were scored across a series of characteristics broadly covering measures of early vitality, drinking ability, learning ability, and personality traits scored in novel environment, human approach, and novel object tests ${ }^{1}$

\begin{tabular}{|c|c|c|c|c|c|}
\hline Variable & Factor 1 & Factor 2 & Factor 3 & Factor 4 & Factor 5 \\
\hline Latency to stand attempt (min)* & 0.68 & -0.16 & 0.10 & -0.14 & -0.35 \\
\hline Latency to stand $(\min )^{*}$ & 0.92 & 0.20 & 0.022 & 0.04 & 0.01 \\
\hline Latency to suckle dam $(\mathrm{min})^{*}$ & 0.75 & 0.09 & 0.29 & 0.07 & 0.17 \\
\hline Vitality score & -0.28 & 0.28 & 0.13 & -0.22 & -0.10 \\
\hline Colostrum drinking score* & 0.27 & 0.11 & 0.72 & 0.04 & 0.08 \\
\hline Milk intake first week $(\mathrm{L} / \mathrm{d})$ & -0.05 & 0.28 & 0.34 & -0.68 & 0.05 \\
\hline Feedings to learn to use group feeder (no.)* & -0.02 & 0.00 & 0.24 & 0.84 & -0.04 \\
\hline Teat demonstrations to learn to use group feeder (no.)* & -0.07 & 0.01 & -0.22 & 0.74 & 0.08 \\
\hline Exploring $^{2,3}$ (\% of time) & 0.13 & -0.35 & -0.14 & -0.09 & 0.56 \\
\hline Active $^{3}$ (no. of quadrants crossed) & -0.15 & 0.06 & 0.15 & 0.18 & 0.66 \\
\hline Inactive $^{3}$ ( $\%$ of time) & 0.02 & -0.22 & -0.40 & 0.27 & -0.1 \\
\hline Vocalizations (no.)* & 0.02 & 0.03 & -0.22 & -0.12 & 0.72 \\
\hline Variance explained (\%) & 23.7 & 14.3 & 11.7 & 9.0 & 7.6 \\
\hline Interpretation (suggested label) & Low vitality & Fearful & Strong drinker & Slow learner & $\begin{array}{c}\text { Exploratory- } \\
\text { active }\end{array}$ \\
\hline
\end{tabular}

${ }^{1}$ Behaviors were averaged across tests except where indicated. High loadings $(\geq 0.50)$ are indicated in bold. Eigenvalues and proportion of total variation explained by each factor are reported, and suggested labels for each factor are offered.

${ }^{2}$ Time spent sniffing, licking, or muzzle close to floor or wall surfaces.

${ }^{3}$ Behavior recorded only in novel environment test.

${ }^{4}$ Calf is observing (head oriented toward) human or object [sum of time spent within 1 body length (close) and more than 1 body length away (far)].

*Variable was transformed to meet requirement of normality ( $\log _{10}$ or square-root transformation).

Table 3. Development of solid feed intake behavior and weaning age, feeding behavior, intake, and growth measures (mean $\pm \mathrm{SD}$, range) for 43 Holstein dairy calves over the experimental period from d 1 to 105 of age

\begin{tabular}{|c|c|c|c|}
\hline Measure & Mean & $\mathrm{SD}$ & Range \\
\hline \multicolumn{4}{|l|}{ Development of solid feed intake behavior ${ }^{1}$} \\
\hline Age to eat $40 \mathrm{~g}$ of solid feed (d) & 36.0 & 12.8 & $18-75$ \\
\hline Age to eat $225 \mathrm{~g} / \mathrm{d}$ of solid feed (d) & 47.2 & 10.9 & $33-78$ \\
\hline Age to eat $675 \mathrm{~g} / \mathrm{d}$ of solid feed (d) & 53.4 & 10.4 & $37-81$ \\
\hline Weaning age (eat 1,300 g/d of solid feed $)^{2}(\mathrm{~d})$ & 59.1 & 9.6 & $44-84$ \\
\hline \multicolumn{4}{|l|}{ Behavior at milk feeder ${ }^{3}$ / } \\
\hline Rewarded visits (total no.) & 407.8 & 116.4 & $212-737$ \\
\hline Unrewarded visits (total no.) & 491.4 & 197.0 & $211-1,160$ \\
\hline Drinking speed $(\mathrm{L} / \mathrm{min})$ & 0.65 & 0.16 & $0.30-1.1$ \\
\hline \multicolumn{4}{|l|}{ Persistent return to milk feeder during first week after weaning } \\
\hline Unrewarded visits (total no.) & 89.0 & 35.8 & $37-197$ \\
\hline \multicolumn{4}{|l|}{ Total feed intake } \\
\hline Milk DMI (kg) & 47.0 & 11.4 & $28.1-76.8$ \\
\hline Calf starter DMI $(\mathrm{kg})$ & 141.7 & 36.5 & $58.3-257.2$ \\
\hline \multicolumn{4}{|l|}{ Growth } \\
\hline $\mathrm{ADG}(\mathrm{kg}$ of $\mathrm{BW} / \mathrm{d})$ & 1.0 & 0.11 & $0.75-1.2$ \\
\hline Final weight $(\mathrm{kg})$ & 147.3 & 15.8 & $118.7-186.8$ \\
\hline
\end{tabular}

${ }^{1}$ Calculated as the average of the previous $3 \mathrm{~d}$, with the requirement that each of the $3 \mathrm{~d}$ met at least $50 \%$ of the target.

${ }^{2}$ Calves that failed to meet the intake target of $1,300 \mathrm{~g} / \mathrm{d}$ by d 84 of age were forced to wean over a 7 -d period and are not included here.

${ }^{3}$ Rewarded refers to a visit where milk was available; unrewarded refers to a visit where milk was not available. 
NEAVE ET AL.

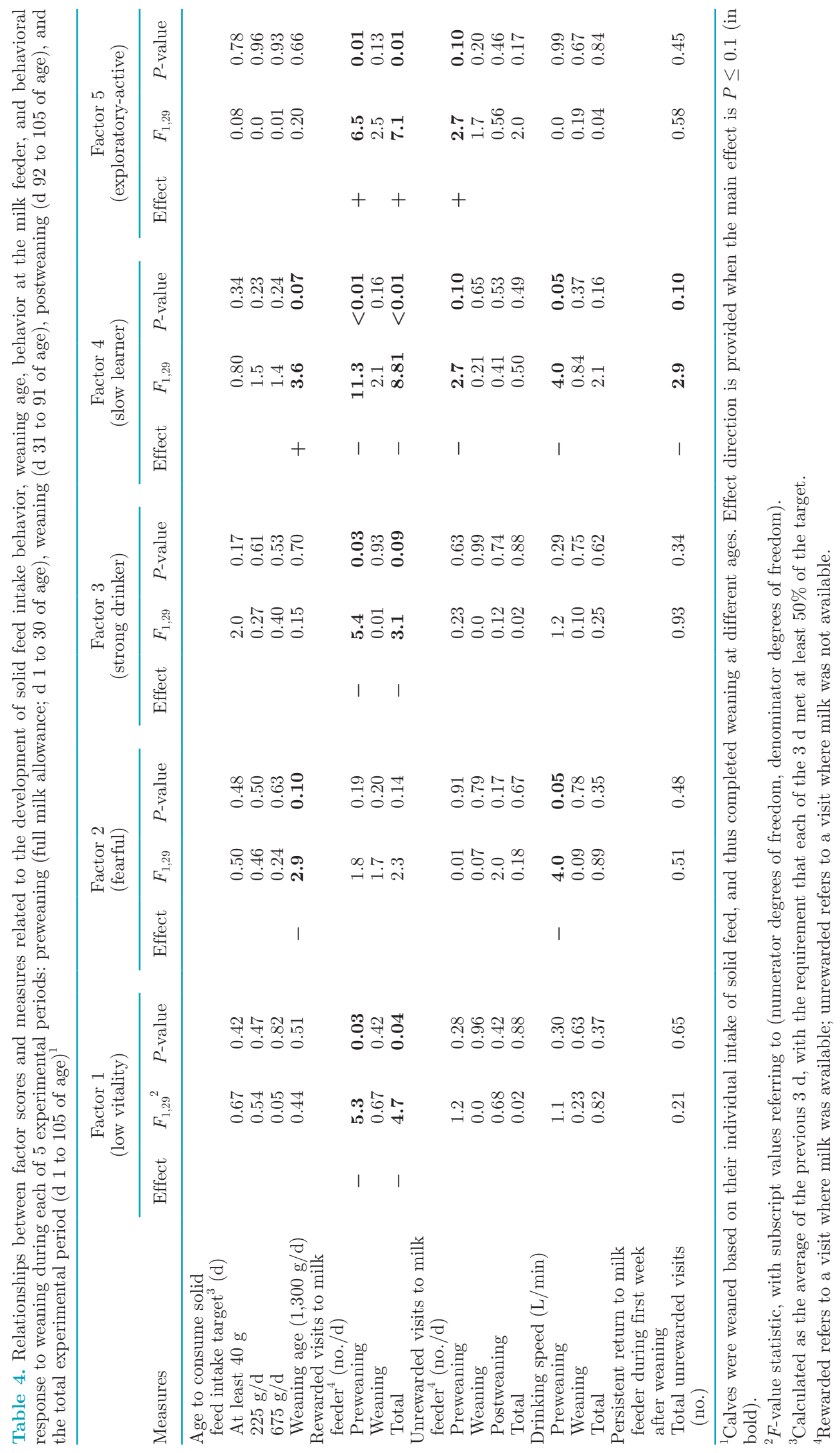


INDIVIDUAL CHARACTERISTICS OF DAIRY CALVES

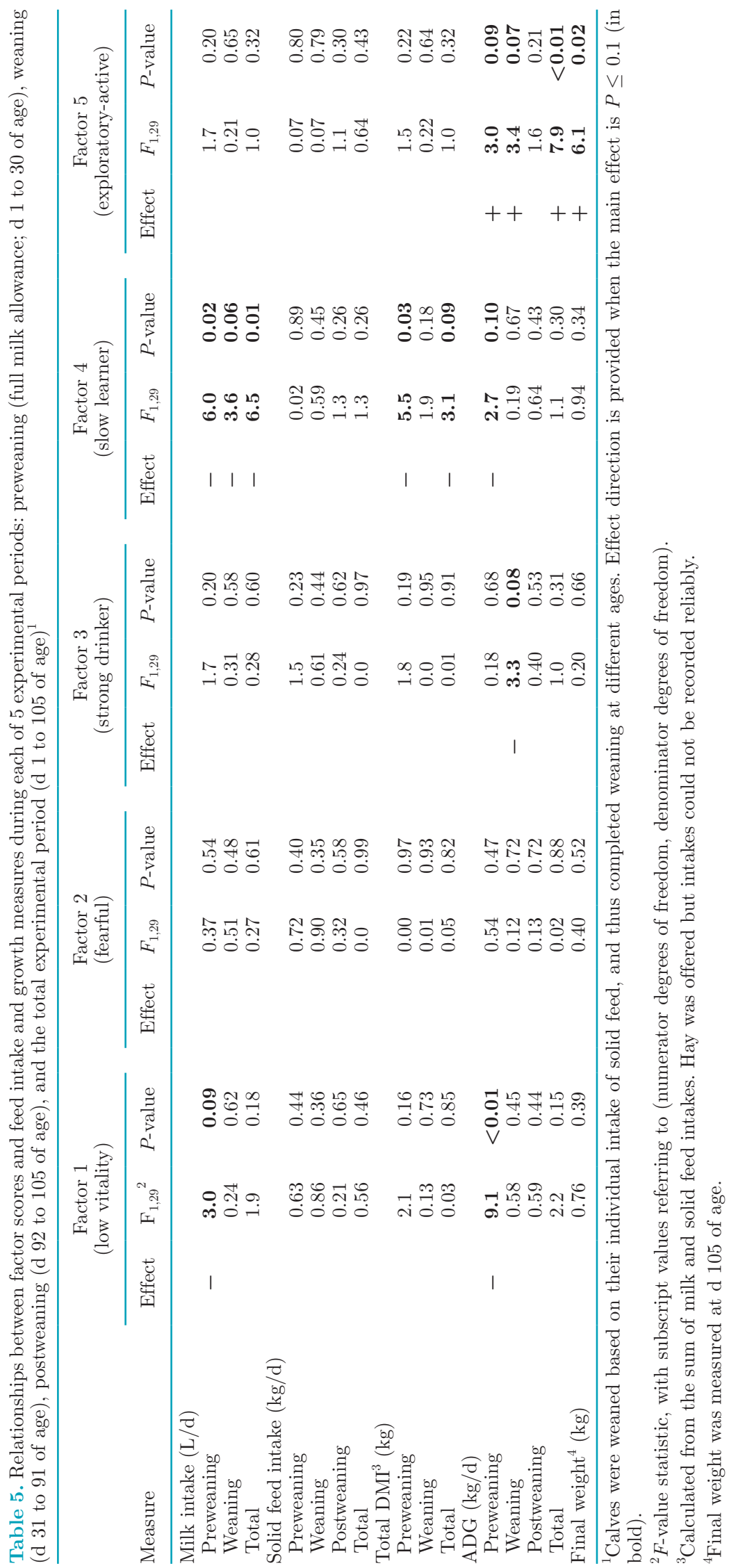



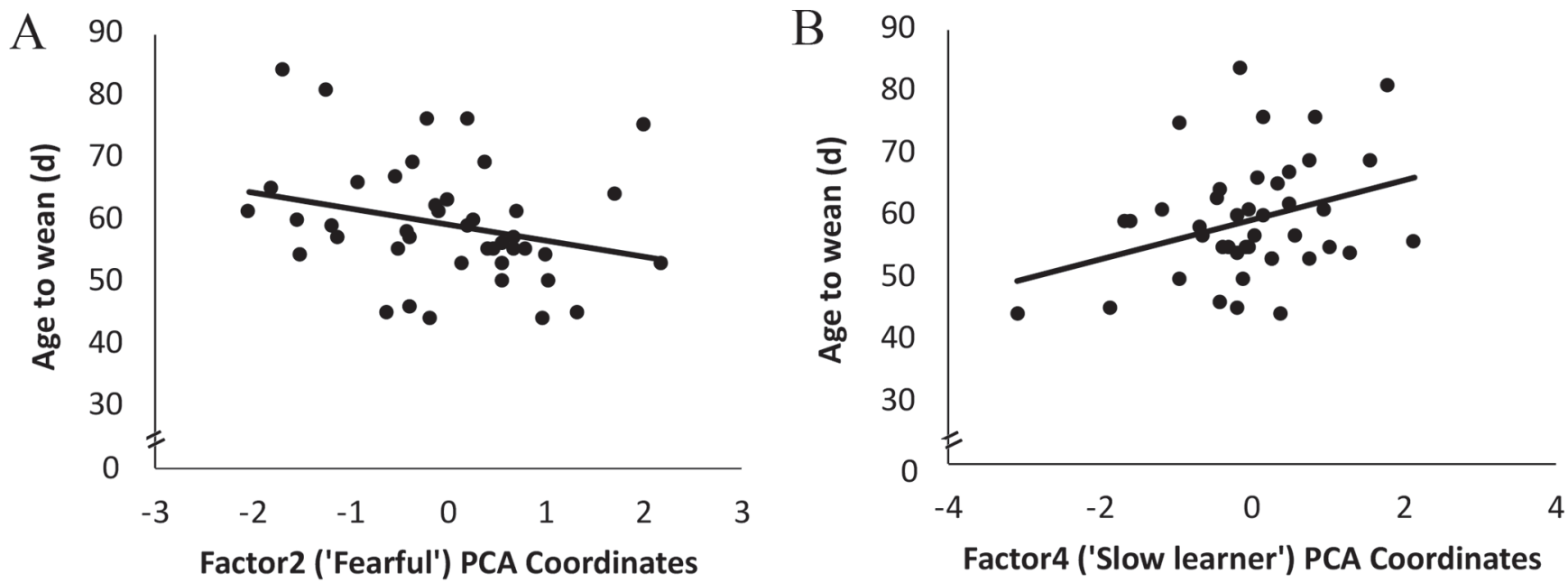

C

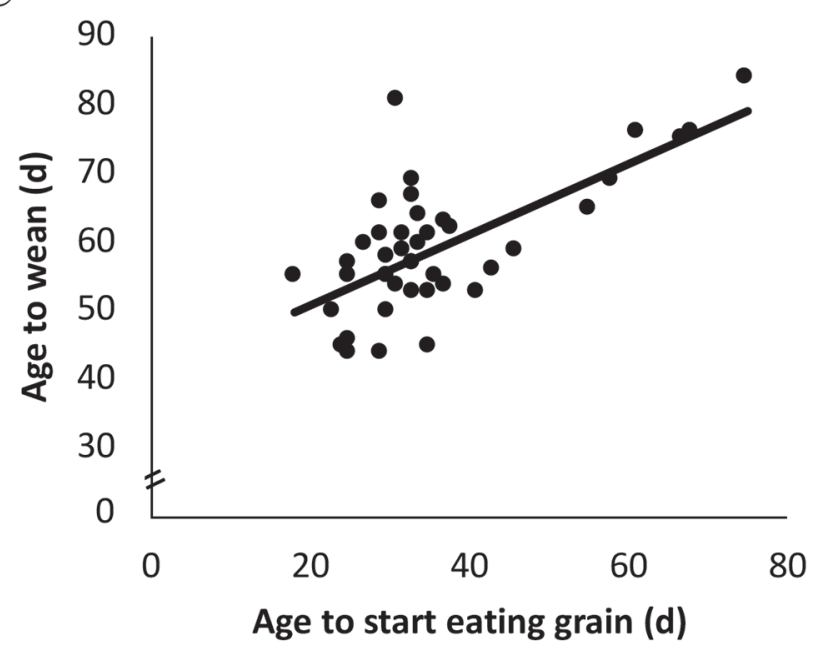

$\mathrm{D}$

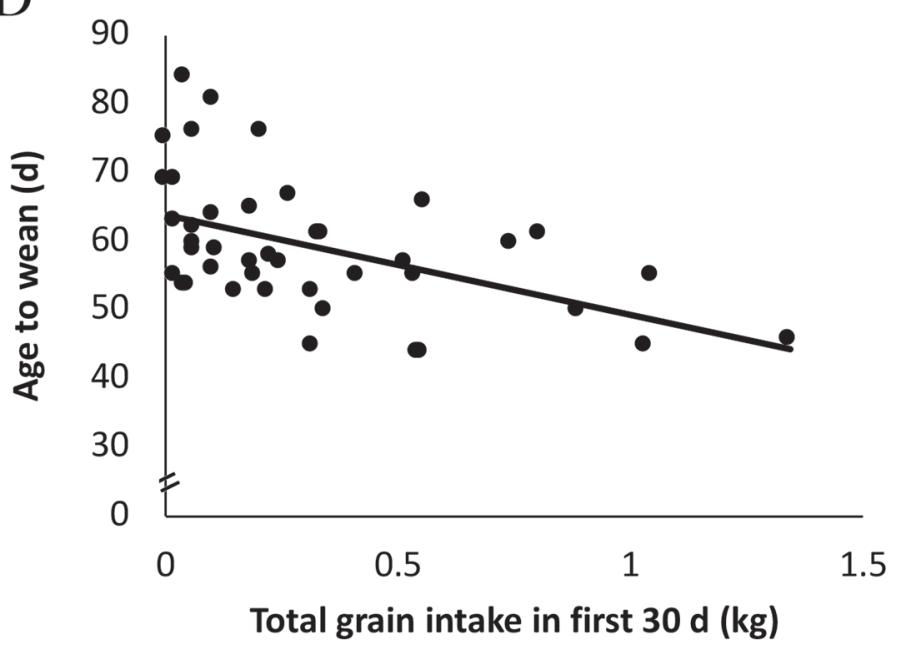

$\mathrm{E}$

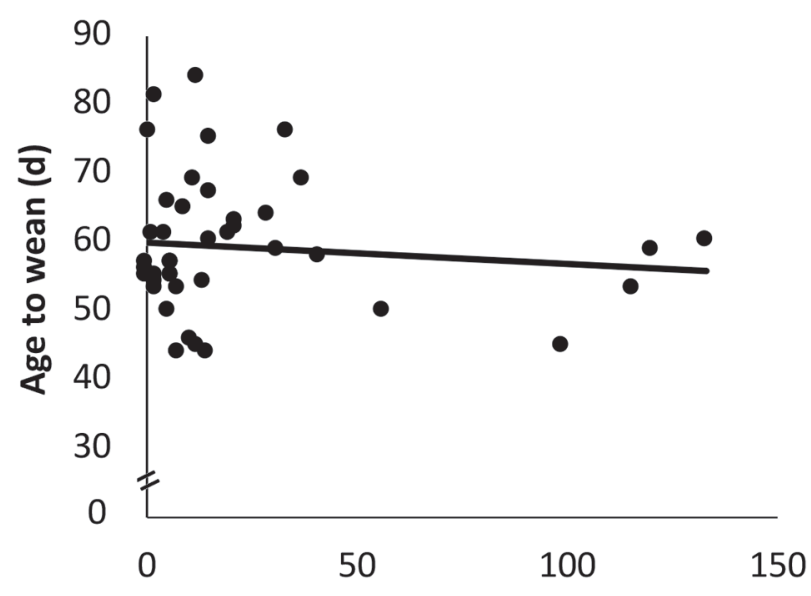

Total unrewarded visits to the milk feeder in first $30 \mathrm{~d}$ (no.)

Figure 1. Relationship between weaning age and (A) factor 2: fearful, (B) factor 4: slow learner, (C) age to start eating calf starter, (D) total calf starter intake in the first $30 \mathrm{~d}$ of age, and (E) total unrewarded visits to the milk feeder in the first $30 \mathrm{~d}$ of age. These variables were retained following a multiple regression analysis with backward elimination that initially included 12 measures of individual characteristics, feeding behavior, and growth in the first $30 \mathrm{~d}$ of age; the final model explained $67 \%$ of the variance in weaning age. PCA $=$ principal component analysis. 
1.45 (factor 4) - 2.23 (factor 2) - 0.039 (total preweaning unrewarded visits).

\section{DISCUSSION}

These results build upon previous work that identified a myriad of associations between personality and feed intake, behavior, and performance around weaning for dairy calves (Neave et al., 2018a). The key difference in the current study is that we used an automated and individualized method of weaning, where calves were allowed to progress through weaning as they consumed increasing amounts of solid feed, resulting in variable weaning ages. This study is also the first to investigate the relationship between individual characteristics measured in early life (vitality at birth, drinking and learning ability, and personality traits) and weaning age, feeding behavior, and performance when calves are weaned automatically based on their intake of solid feed. We also investigated if measures taken in the first $30 \mathrm{~d}$ of life could be used to predict weaning age of dairy calves.

\section{Individual Variability in Weaning Age, Feeding Behavior, and Performance}

Solid feed intake early in life facilitates weaning from milk, yet few studies describe the variability in solid feed intake in preweaned calves. We found a large range in ages when calves began to consume calf starter (between 18 and $75 \mathrm{~d}$ of age) and when calves reached 225 and $675 \mathrm{~g} / \mathrm{d}$ of calf starter (between 33 and $81 \mathrm{~d}$ of age), a result consistent with that reported in earlier studies (de Passillé and Rushen, 2016; Neave et al., 2018a; Benetton et al., 2019). In the current study, some calves weaned as early as $44 \mathrm{~d}$, whereas others were as old as $84 \mathrm{~d}$ before they met the final solid feed intake target. Weaning age ranged considerably in previous studies that weaned calves based on intake of solid feed, both when calves received ad libitum or restricted allowances of milk (Roth et al., 2009; de Passillé and Rushen, 2012, 2016). Collectively, this body of work highlights that calves vary in their intake of solid feed in ways that affect success at weaning.

We also found individual variability in milk and calf starter intake, feeding behaviors, and performance. Variability in preweaning milk intakes has been shown in other studies that fed calves high amounts of milk (Rosenberger et al., 2017; Dennis et al., 2018). Measures of feeding behavior at the milk feeder, including the frequency of visits to the milk feeder and drinking speed, were highly variable across calves, a finding that to our knowledge has not previously been reported.
These individual differences likely contribute to the variability in preweaning weight gains. In the current study, preweaning ADG ranged from 0.3 to $1.3 \mathrm{~kg} / \mathrm{d}$. This result corresponds well with results from earlier work reporting 0.3 to $1.3 \mathrm{~kg} / \mathrm{d}$ to d 50 of age (Soberon et al., 2012) and 0.1 to $1.2 \mathrm{~kg} / \mathrm{d}$ to $\mathrm{d} 30$ of age (de Passillé et al., 2016).

Efforts to understand the source of this individual variation have typically focused on external factors such as housing, feeding, health, and climate (e.g., Place et al., 1998; Shivley et al., 2018), and internal factors have been largely overlooked. Neave et al. (2018a) showed that personality differences among calves could explain variability in weight gains, and de Passillé and Rushen (2016) suggested differences in weaning age (when weaned based on solid feed intake) may be related to gastrointestinal differences, taste preferences, or ability to recognize a new food source. To add to this body of work, we measured several calf behaviors in the first few weeks of life and related these to variability in weaning age, feeding behavior, and performance of calves in the first 15 wk of age.

\section{Vitality at Birth}

Calves with a longer duration to reach sternal recumbency, attempt to stand, stand, walk, and suckle the dam in the hours after birth were identified as having low vitality in the PCA. Our findings did not indicate that low vitality calves show delayed solid feed intakes and weaning. However, low vitality was associated with reduced preweaning milk intake.

Longer latencies to reach sternal recumbency and to suckle from the dam after birth have been attributed to a difficult birth (Barrier et al., 2012; Murray and Leslie, 2013), and may contribute to reduced colostrum intake (Vasseur et al., 2009), failure of passive transfer, and reduced weight gain (Furman-Fratczak et al., 2011). We found that low vitality calves had reduced preweaning weight gains, but this is unlikely to be related to inadequate colostrum intake since all our calves received at least $4 \mathrm{~L}$ of colostrum and all achieved passive transfer. Other work has found that low vitality is negatively associated with early milk intake (Fujiwara et al., 2014; de Passillé et al., 2016), but the association is less clear for weight gain (positive association: Murray et al., 2015; no association: de Passillé et al., 2016). The differences across these studies may be related to the timing of measurements (either at birth, or several days later). Future research should investigate if the behavioral development of calves with low vitality is related to a difficult birth or other individual factors (e.g., physiological and metabolic status) leading to low 
thrift, and how this may affect low preweaning milk intake and weight gain.

\section{Drinking Ability}

Calves that had high colostrum and first-milk-meal drinking scores (i.e., quickly consumed their full meal) were termed strong drinkers in the PCA. We found no association between this trait and the development of solid feed intake behavior, weaning age, feed intake, or growth. Similarly, de Passillé et al. (2016) found that milk intake at d 2 to 3 of age was not related to energy intake or weight gain in the first month of life, although milk intake at d 4 did have some associations with these later measures. Although we did not identify a relationship between drinking ability at d 1 of age and later drinking speed, the strong drinkers did have fewer preweaning visits to the milk feeder and reduced weight gain during weaning. It is unclear why these calves had fewer preweaning visits to the milk feeder, but reduced weight gain may indicate that these calves were more distressed when milk was removed. High early milk intake or drinking strength may be an indicator that calves need assistance when weaned based on solid feed intake. These calves may perform better on a weaning program that removes milk more gradually at each solid feed intake target.

\section{Learning Ability}

Calves that required extensive training to learn to use the automated milk feeder and had reduced milk intake in the first week were termed slow learners in the PCA. We found that these slower learners weaned at a later age. These calves also had reduced milk intake, drinking speed, visits to the milk feeder, and growth before weaning, and fewer unrewarded visits to the milk feeder in the week after weaning; this result suggests that these calves were less persistent in attempting to gain milk from the feeder, which may indicate a reduced motivation to drink milk. Other work has shown a negative correlation between latency to drink unassisted from the automated feeder and milk intake in the first $2 \mathrm{wk}$ (Fujiwara et al., 2014) and weight gain in the first month (Medrano-Galarza et al., 2018). We speculate that these slow learners may be less resourceful when it comes to maximizing milk intake during the milk-feeding period and solid feed intake in the later stages of weaning, resulting in a later weaning age when weaned based on solid feed intake. These calves may also have difficulty learning from social cues of other calves about their feeding environment, as the development of feeding behaviors can be enhanced through social facilitation and learning from other members of the herd (reviewed in Launchbaugh and Howery, 2005). These calves that were slow to learn to use the milk feeder may also have been slow to learn to use the feeder dispensing solid feed. Future work should investigate the influence of these different factors on weaning age.

The training required for calves to learn to use the milk feeder may be measured relatively easily, as automated feeders can be programmed to alarm if calves fail to come to the feeder on their own. Further research is necessary to understand why some calves struggle to learn to use the milk feeding equipment; for instance, some work has found that the stall design around the milk feeder may delay learning (Wilson et al., 2018). Improved training methods may contribute to improving feed intake, behavior, and weaning age.

\section{Fearful and Exploratory-Active Personality Traits}

The PCA identified 2 main personality traits based on the behavior expressed during the standardized novelty tests: fearful (factor 2) and exploratory-active (factor 5). Fearful calves tended to wean at an earlier age but were not associated with other measures of development of solid feed intake behaviors. This was contrary to our hypothesis that more fearful calves (i.e., more reactive to a novel object and human) would also be more reactive to a change in their feeding environment during our weaning program (i.e., milk removal based on increasing intake of solid feed). Fearful calves were more attentive in the novelty tests, which may indicate they are more attentive and responsive to changes in their environment (e.g., by increasing solid feed intake in response to milk removal to complete weaning earlier). Research on lambs has shown that fear responses do not translate to a feeding context (Rice et al., 2016). We found that fearful calves had reduced preweaning drinking speed, which may be an indication of low feeding motivation or reflect a preferred feeding rate that is characteristic for these calves (Nielsen, 1999), so these calves may not see milk removal as particularly stressful. We encourage further work to understand why fearful calves appear to wean earlier than others and how these specific personality traits influence how calves cope with other management changes.

The personality trait exploratory-active was not associated with the development of solid feed intake behaviors or weaning age in this study. This finding contrasts with our previous work that found that exploratory calves consumed more solid feed at earlier ages when weaned at a fixed age (Neave et al., 2018a). However, our exploratory-active calves had improved weight gain throughout the experiment resulting in 
greater final weight, similar to our previous study and other work in beef heifers (Müller and von Keyserlingk, 2006). The improved weight gain observed in these calves was not associated with increased milk or calf starter intake, suggesting that these calves may cope well with the weaning transition. We speculate these results are related to the weaning method since the current study removed portions of milk as each individual reached a solid feed intake target; individuals clearly differed in how they responded to this method of milk removal (either by continuing to increase solid feed intake, or trying to regain milk and delaying solid feed intake), resulting in variable weaning ages. Further research should investigate how different personality traits respond to different methods of milk removal during gradual weaning so that appropriate methods of weaning can be identified for different individuals.

Overall, we found that calves differed in how they responded to an automated weaning program; slow learner and fearful characteristics were associated with weaning age (and thus age to consume 1,300 g/d of solid feed), which could be used to identify calves from an early age that may do well or struggle during weaning. However, the early-life characteristics measured in this study had limited associations with the early development of solid feed intake behaviors. Other characteristics such as sociability and food neophobia explain some variability in feeding behaviors of ruminants (see review by Neave et al., 2018b), and may be related to early intake of solid feed. In addition, there is a need to identify automated methods of characterizing dairy calves, especially for exploration-activity and fearfulness, as currently it is likely not feasible to collect these measures on-farm. Automated activity monitors (Swartz et al., 2016), or the response to an approaching human during feeding (Lensink et al., 2003; Rousing et al., 2005), are examples of practical assessment methods that should be verified for associations with weaning age, feeding behavior, and performance.

\section{Predicting Weaning Age}

It would be advantageous to identify calves at an early age that are able to wean earlier, especially on farms that still manually feed and wean their calves; milk is an expensive resource that could be better allocated toward calves that need more time to make the transition to solid feed. We found that early measures of calf starter intake (age to begin eating calf starter, and total calf starter intake in the first $30 \mathrm{~d}$ of age) were the best predictors of weaning age, explaining a large portion of the variability in weaning age. These measures are relatively easy to monitor in manually fed calves. About $30 \%$ of the variation in weaning age remained unexplained by the measures collected in this study. Future research should integrate multiple technologies and machine learning models (e.g., Borchers et al., 2017) to better identify calves that require more time before weaning (e.g., rumination activity or rumen $\mathrm{pH})$.

\section{CONCLUSIONS}

Weaning age is variable when calves are weaned based on their intake of solid feed. Some individual characteristics measured in early life (slow to learn to use the automated milk feeder, and fearful personality), and measures of early calf starter intake, can identify calves that will wean earlier in an automated weaning program based on solid feed intake. Low vitality at birth, drinking ability, and exploratory-active personality are also associated with feed intake, behavior, and performance. Future work should investigate additional animal-based measures (especially those that can be automatically monitored and feasibly measured onfarm) that can identify calves that are likely to do well or struggle during weaning.

\section{ACKNOWLEDGMENTS}

We thank the staff and students of the University of British Columbia Dairy Education and Research Centre who helped with data collection in this experiment, especially Stephanie Boeve, Julie Wong, Cheryl Linaksita, Ana Carolina Moncada, Allison Welk, and Jennifer Van Os. A Natural Sciences and Engineering Research Council (NSERC) Discovery Grant to MvK provided funds for the work on personality summarized in this study. The results summarizing the feeding behavior and weight gains were supported by Canada's NSERC Industrial Research Chair Program awarded to MvK and DMW with industry contributions from the Dairy Farmers of Canada (Ottawa, ON, Canada), British Columbia Dairy Association (Burnaby, BC Canada), Westgen Endowment Fund (Milner, BC, Canada), Intervet Canada Corporation (Kirkland, QC, Canada), Novus International Inc. (Oakville, ON, Canada), Zoetis (Kirkland, QC, Canada), BC Cattle Industry Development Fund (Kamloops, BC, Canada), Alberta Milk (Edmonton, AB, Canada), Valacta (St. Anne-de-Bellevue, QC, Canada), and CanWest DHI (Guelph, ON, Canada).

\section{REFERENCES}

Barrier, A. C., E. Ruelle, M. J. Haskell, and C. M. Dwyer. 2012. Effect of a difficult calving on the vigour of the calf, the onset of 
maternal behaviour, and some behavioural indicators of pain in the dam. Prev. Vet. Med. 103:248-256. https://doi.org/10.1016/j .prevetmed.2011.09.001.

Benetton, J. B., H. W. Neave, J. H. C. Costa, M. A. G. von Keyserlingk, and D. M. Weary. 2019. Automatic weaning based on individual solid feed intake: Effects on behavior and performance of dairy calves. J. Dairy Sci. 102:5475-5491. https://doi.org/10 .3168/jds.2018-15830.

Borchers, M., Y. Chang, K. Proudfoot, B. Wadsworth, A. Stone, and J. Bewley. 2017. Machine-learning-based calving prediction from activity, lying, and ruminating behaviors in dairy cattle. J. Dairy Sci. 100:5664-5674. https://doi.org/10.3168/jds.2016-11526.

Bovine Alliance on Management and Nutrition. 2017. A Guide to Feeding and Weaning Healthy and Productive Dairy Calves. Accessed Nov. 5, 2017. https://www.aphis.usda.gov/animal_health/ nahms/dairy/downloads/bamn/BAMN17_GuideFeeding.pdf.

de Passillé, A. M., T. F. Borderas, and J. Rushen. 2011. Weaning age of calves fed a high milk allowance by automated feeders: Effects on feed, water, and energy intake, behavioral signs of hunger, and weight gains. J. Dairy Sci. 94:1401-1408. https://doi.org/10.3168/ jds.2010-3441.

de Passillé, A. M., M. Rabeyrin, and J. Rushen. 2016. Associations between milk intake and activity in the first days of a calf's life and later growth and health. Appl. Anim. Behav. Sci. 175:2-7. https:/ /doi.org/10.1016/j.applanim.2014.10.002.

de Passillé, A. M., and J. Rushen. 2012. Adjusting the weaning age of calves fed by automated feeders according to individual intakes of solid feed. J. Dairy Sci. 95:5292-5298. https://doi.org/10.3168/ jds.2012-5521.

de Passillé, A. M., and J. Rushen. 2016. Using automated feeders to wean calves fed large amounts of milk according to their ability to eat solid feed. J. Dairy Sci. 99:3578-3583. https://doi.org/10 $.3168 /$ jds.2015-10259.

Dennis, T. S., F. X. Suarez-Mena, T. M. Hill, J. D. Quigley, R. L. Schlotterbeck, and L. Hulbert. 2018. Effect of milk replacer feeding rate, age at weaning, and method of reducing milk replacer to weaning on digestion, performance, rumination, and activity in dairy calves to 4 months of age. J. Dairy Sci. 101:268-278. https:/ /doi.org/10.3168/jds.2017-13692.

Fujiwara, M., J. Rushen, and A. M. de Passillé. 2014. Dairy calves adaptation to group housing with automated feeders. Appl. Anim. Behav. Sci. 158:1-7. https://doi.org/10.3168/jds.2010-3253.

Furman-Fratczak, K., A. Rzasa, and T. Stefaniak. 2011. The influence of colostral immunoglobulin concentration in heifer calves' serum on their health and growth. J. Dairy Sci. 94:5536-5543. https:// doi.org/10.3168/JDS.2010-3253.

Gelsinger, S. L., A. J. Heinrichs, and C. M. Jones. 2016. A metaanalysis of the effects of preweaned calf nutrition and growth on first-lactation performance. J. Dairy Sci. 99:6206-6214. https:// doi.org/10.3168/jds.2015-10744.

Gilbert, M. S., J. J. G. C. van den Borne, C. G. van Reenen, and W. J. J. Gerrits. 2017. Only 7\% of the variation in feed efficiency in veal calves can be predicted from variation in feeding motivation, digestion, metabolism, immunology, and behavioral traits in early life. J. Dairy Sci. 100:8087-8101. https://doi.org/10.3168/jds.2016 -12390 .

Heinrichs, A. J., and B. S. Heinrichs. 2011. A prospective study of calf factors affecting first-lactation and lifetime milk production and age of cows when removed from the herd. J. Dairy Sci. 94:336-341. https://doi.org/10.3168/jds.2010-3170.

Hötzel, M. J., C. Longo, L. F. Balcão, C. S. Cardoso, and J. H. C. Costa. 2014. A survey of management practices that influence performance and welfare of dairy calves reared in Southern Brazil. PLoS One 9:e114995. https://doi.org/10.1371/journal.pone.0114995.

Launchbaugh, K. L., and L. D. Howery. 2005. Understanding landscape use patterns of livestock as a consequence of foraging behavior. Rangeland Ecol. Manag. 58:99-108. https://doi.org/10.2111/ 03-146.1.

Lecorps, B., D. M. Weary, and M. A. G. von Keyserlingk. 2018. Pessimism and fearfulness in dairy calves. Sci. Rep. 8:1421. https:// doi.org/10.1038/s41598-017-17214-3.
Lensink, B., C. van Reenen, B. Engel, T. Rodenburg, and I. Veissier. 2003. Repeatability and reliability of an approach test to determine calves' responsiveness to humans: A brief report. Appl. Anim. Behav. Sci. 83:325-330. https://doi.org/10.1016/S0168 -1591(03)00138-2.

Medrano-Galarza, C., S. J. LeBlanc, T. J. DeVries, A. Jones-Bitton, J. Rushen, A. Marie de Passillé, M. I. Endres, and D. B. Haley. 2018. Effect of age of introduction to an automated milk feeder on calf learning and performance and labor requirements. J. Dairy Sci. 101:9371-9384. https://doi.org/10.3168/jds.2018-14390.

Müller, R., and M. A. G. von Keyserlingk. 2006. Consistency of flight speed and its correlation to productivity and to personality in Bos taurus beef cattle. Appl. Anim. Behav. Sci. 99:193-204. https:// doi.org/10.1016/j.applanim.2005.05.012.

Murray, C. F. 2014. Characteristics, risk factors and management programs for vitality of newborn dairy calves. PhD Thesis, Department of Population Medicine, University of Guelph, Ontario, Canada.

Murray, C. F., and K. E. Leslie. 2013. Newborn calf vitality: Risk factors, characteristics, assessment, resulting outcomes and strategies for improvement. Vet. J. 198:322-328. https://doi.org/10.1016/j .tvj1.2013.06.007

Murray, C. F., D. M. Veira, A. L. Nadalin, D. M. Haines, M. L. Jackson, D. L. Pearl, and K. E. Leslie. 2015. The effect of dystocia on physiological and behavioral characteristics related to vitality and passive transfer of immunoglobulins in newborn Holstein calves. Can. J. Vet. Res. 79:109-119.

Neave, H. W., J. H. C. Costa, D. M. Weary, and M. A. G. von Keyserlingk. 2018a. Personality is associated with feeding behavior and performance in dairy calves. J. Dairy Sci. 101:7437-7449. https:// doi.org/10.3168/jds.2017-14248.

Neave, H. W., D. M. Weary, and M. A. G. von Keyserlingk. 2018b. Review: Individual variability in feeding behaviour of domesticated ruminants. Animal 12:s419-s430. https://doi.org/10.1017/ S1751731118001325.

Nielsen, B. L. 1999. On the interpretation of feeding behaviour measures and the use of feeding rate as an indicator of social constraint. Appl. Anim. Behav. Sci. 63:79-91. https://doi.org/10 .1016/S0168-1591(99)00003-9

Nielsen, P. P., M. B. Jensen, and L. Lidfors. 2008. Milk allowance and weaning method affect the use of a computer controlled milk feeder and the development of cross-sucking in dairy calves. Appl. Anim. Behav. Sci. 109:223-237. https://doi.org/10.1016/j.applanim.2007 .01 .015 .

Place, N. T. A. J. Heinrichs, and H. N. Erb. 1998. The effects of disease, management, and nutrition on average daily gain of dairy heifers from birth to four months. J. Dairy Sci. 81:1004-1009.

Raeth-Knight, M., H. Chester-Jones, S. Hayes, J. Linn, R. Larson, D. Ziegler, B. Ziegler, and N. Broadwater. 2009. Impact of conventional or intensive milk replacer programs on Holstein heifer performance through six months of age and during first lactation. J. Dairy Sci. 92:799-809. https://doi.org/10.3168/jds.2008-1470.

Rice, M., E. C. Jongman, S. Borg, K. L. Butler, and P. H. Hemsworth. 2016. Characterisation of shy-feeding and feeding lambs in the first week in a feedlot. Appl. Anim. Behav. Sci. 179:39-45. https://doi .org/10.1016/j.applanim.2016.03.011.

Rosenberger, K., J. H. C. Costa, H. W. Neave, M. A. G. von Keyserlingk, and D. M. Weary. 2017. The effect of milk allowance on behavior and weight gains in dairy calves. J. Dairy Sci. 100. https: //doi.org/10.3168/jds.2016-11195.

Roth, B. A., N. M. Keil, L. Gygax, and E. Hillmann. 2009. Influence of weaning method on health status and rumen development in dairy calves. J. Dairy Sci. 92:645-656. https://doi.org/10.3168/ jds.2008-1153.

Rousing, T., B. Ibsen, and J. T. Sørensen. 2005. A note on: On-farm testing of the behavioural response of group-housed calves towards humans; test-retest and inter-observer reliability and effect of familiarity of test person. Appl. Anim. Behav. Sci. 94:237-243. https: //doi.org/10.1016/j.applanim.2005.02.011.

Shivley, C. B., J. E. Lombard, N. J. Urie, C. A. Kopral, M. Santin, T. J. Earleywine, J. D. Olson, and F. B. Garry. 2018. Preweaned 
heifer management on US dairy operations: Part VI. Factors associated with average daily gain in preweaned dairy heifer calves. J. Dairy Sci. 101:9245-9258. https://doi.org/10.3168/jds.2017-14022.

Soberon, F., E. Raffrenato, R. W. Everett, and M. E. Van Amburgh. 2012. Preweaning milk replacer intake and effects on long-term productivity of dairy calves. J. Dairy Sci. 95:783-793. https://doi .org/10.3168/jds.2011-4391.

Staněk, S., V. Zink, O. Doležal, and L. Štolc. 2014. Survey of preweaning dairy calf-rearing practices in Czech dairy herds. J. Dairy Sci. 97:3973-3981. https://doi.org/10.3168/jds.2013-7325.

Swartz, T. H., M. L. McGilliard, and C. S. Petersson-Wolfe. 2016. Technical note: The use of an accelerometer for measuring step activity and lying behaviors in dairy calves. J. Dairy Sci. 99:91099113. https://doi.org/10.3168/jds.2016-11297.

Vannucchi, C. I., J. A. Rodrigues, L. C. G. Silva, C. F. Lúcio, and G. A. L. Veiga. 2012. A clinical and hemogasometric survey of neo- natal lambs. Small Rumin. Res. 108:107-112. https://doi.org/10 .1016/j.smallrumres.2012.05.013.

Vasseur, E., F. Borderas, R.I. Cue, D. Lefebvre, D. Pellerin, J. Rushen, K.M. Wade, and A. M. de Passille. 2010. A survey of dairy calf management practices in Canada that affect animal welfare. J. Dairy Sci. 93:1307-1315. https://doi.org/10.3168/jds.2009-2429.

Vasseur, E., J. Rushen, and A. M. de Passille. 2009. Does a calf's motivation to ingest colostrum depend on time since birth, calf vigor or provision of heat? J. Dairy Sci. 92:3915-3921. https://doi.org/ $10.3168 /$ jds.2008-1823.

Wilson, T. R., S. J. LeBlanc, T. J. DeVries, and D. B. Haley. 2018. Effect of stall design on dairy calf transition to voluntary feeding on an automatic milk feeder after introduction to group housing. J. Dairy Sci. 101:5307-5316. https://doi.org/10.3168/jds.2017-14011. 